\title{
Jumping of Camelid Coronavirus in Bovines: A Report from Rural Area of Haryana, India
}

Minakshi $\mathrm{P}^{1 *}$, Brar $\mathrm{B}^{1}$, Ikbal ${ }^{1}$, Ranjan $\mathrm{K}^{2}$, Singh $\mathrm{I}^{3}$, Nehra $\mathrm{V}^{4}$ and Misri J5

${ }^{1}$ Department of Animal Biotechnology, LLR University of Veterinary and Animal Sciences, India

${ }^{2}$ Department of Veterinary Physiology and Biochemistry, SVP University of Agriculture and Technology, India

${ }^{3}$ Department of Biotechnology, CDLU, India

${ }^{4}$ Department of Veterinary Pathology, LLR University of Veterinary and Animal Sciences, India

${ }^{5}$ Division of Animal Science, Krishi Bhavan, India

*Corresponding author: Minakshi Prasad, Department of Animal Biotechnology, LLR University of Veterinary and Animal Sciences, Hisar, India, Email: minakshi.abt@luvas.edu.in

\section{Abstract}

Bovine coronaviruses (BCoVs) are generally species specific, but cross species transmission has been demonstrated experimentally. Several examples have represented the infection of humans by coronavirus. Most of the coronaviruses are found in domestic as well as wild animals, and it is possible that they arose in human population though zoonotic transmission. In the present study, we evaluated presence of bovine corona virus (BCoV) in bovine fecal samples and reported the infection using RT-PCR assay. BCoV was detected using trans-membrane (M) gene specific RT-PCR with 523 bp amplicon size. A total three hundred thirteen (313) bovine fecal samples were collected for the present study. Out of 313 buffalo fecal samples, 31 buffalo were found infected with coronavirus by RT-PCR assay. The results suggest that RTPCR is sensitive and specific method to detect BCoV, especially in subclinical cases. These results were further confirmed by sequencing of PCR products. The phylogenetic analysis showed that BCoV strains ABT/16/BF/Bocv183, ABT/BF/16/Bocv164 and ABT/BF/16/Bocv86 have close association with bovine strains from USA and Japan. However, ABT/BF/16/Bocv167 strain formed a separate clad along with camelid coronavirus strains and revealed the cross species transmission from camel to bovine. To the best of our knowledge this is the first report of interspecies transmission of coronavirus form camel to bovine.

Keywords: Bovine Corona Virus; Camelid; M Gene; Phylogenetic Analysis; RT-PCR 


\section{Open Access Journal of Veterinary Science \& Research}

\section{Introduction}

Infectious diarrhea is responsible for major cause for neonatal calf mortality and economic losses in dairy farms [1]. It has been recognized as major death causing disease among infectious diseases. Therefore, it has great importance in animal health and especially in dairy industry [2]. Although there are several infectious agents are responsible for neonatal calf diarrhea, several viruses such as bovine rotavirus, bovine viral diarrhea virus, bovine coronavirus and some of the bacterial species $(E$. coli, Salmonella species and Cryptosporidium sp.) are main responsible agents for $75-95 \%$ of infection in neonatal calves [3-5]. Rotaviruses are the considered as leading cause of calf diarrhoea. However, coronaviruses are known for major contributor of calf diarrhea [6]. Economically significant coronavirus of farm animals includes porcine corona virus and bovine corona virus, both results in diarrhea in young animals. Feline corona virus has its two forms, one is feline enteric corona virus is pathogen of minor clinical significance. However, the spontaneous mutations lead to conversion of enteric corona virus in to feline infectious peritonitis which is associated with high mortality in felines. Canine coronavirus also causes two types of illness in canine viz., mild gastrointestinal and respiratory disease. Mouse hepatitis virus is a corona virus that causes an epidemic murine illness with high mortality, especially among colonies of experimental mice [7]. The diseases associated with $\mathrm{BCoV}$ are more intense because they affect both large as well as small intestines $[8,9]$. The incidence of $\mathrm{BCoV}$ is found higher in diarrheic calves than the apparently healthy calves. RT-PCR based study has shown the incidence of up to $64 \%$ in diarrheic bovine calves as compared to $46 \%$ in apparently healthy calves [10]. BCoV causes three different clinical syndromes viz., cattle calf diarrhea, shipping fever in cattle and respiratory infections in cattle and winter dysentery with hemorrhagic diarrhea in adults of various ages [11]. Recent study indicates that $\mathrm{BCoV}$ is a second only causative agent for respiratory infection after bovine herpesvirus [9]. The serological study also suggests that most of the global cattle populations are exposed to $\mathrm{BCoV}$ infection during their lifetime [9]. BCoV of genus Beta coronavirus is also closely related to human coronavirus, SARS-CoV and MERS-CoV [12-14]. However, they are classified within genus Beta, they belong to different lineages. $\mathrm{BCoVs}$ belong to lineage a while, SARS-CoV and MERS-CoV belong to lineages $b$ and $c$, respectively [15].

$\mathrm{BCoV}$ belongs to genus beta of coronaviruses, order Nidovirales and possesses positive sense single-stranded (ss), non-segmented RNA of $32 \mathrm{~kb}$ genome under enveloped capsid [16]. It contains five structural proteinsnucleocapsid $(\mathrm{N})$, transmembrene $(\mathrm{M})$, haemagglutinnin or esterase (HE), spike (S) and small membrane (E) proteins [17]. Commonly, it affects neonatal bovines from day 1 to 3 months of age and diarrhea generally occurs between 2 to 8 weeks of age [18]. These viruses were reported to be frequently found in both normal and diarrheic faces of calves [19].

$\mathrm{BCoV}$ transmission occur either by fecal-oral or respiratory route [9]. It may affect epithelial cells of respiratory and intestinal tract [20]. After replication, $\mathrm{BCoV}$ are usually released in nasal secretions and feces. However, important factors of pathogenesis such as how the virus infects enterocytes are still not fully determined. Many of the experimental studies have suggested that $\mathrm{BCoV}$ hides in feces of diarrheic calves and later on infects the feedlots [21]. Recent studies have suggested that $\mathrm{BCoV}$ is able to overcome host range barriers and even to transmit to humans [22-24]. Interspecies transmission and potential infection of humans with BCoVs has been observed [25]. Interspecies transmission of CoVs was experimentally confirmed by Hasoksuz, et al. [26]. The bovine CoVs like virus (BCoV strain DB2) successfully infected the gnotobiotic (Gn) calves from captive wild ruminants (CWRs) and turkey poults [27]. Bat is known reservoir of CoVs. Previous outbreaks of Middle East Respiratory Syndrome (MERS), Severe Acute Respiratory Syndrome (SARS) and Swine Acute Diarrhea Syndrome (SADS) have been associated with Bat in China, which may also lead to future outbreak in human and livestock population [28]. BCoV is globally distributed and has been reported from several countries of the world [29-32]. However, epidemiological and pathological reports on $\mathrm{BCoV}$ in India are scanty. Therefore, present study was conducted for screening of bovine fecal samples for $\mathrm{BCoV}$ infection using RT-PCR followed by nucleic acid sequencing.

\section{Materials and Methods}

\section{Sample Collection}

A total of three hundred thirteen (313) diarrheic fecal samples from male and female buffalo calves were collected in winter season of 2016, from organized farms of different locations nearby Hisar, Haryana including veterinary college small animal clinics and animal farms from Bhiwani, Jind, Mewat and Meerut district. Fecal samples for screening were collected from suspected animals in screw-capped plastic vials and transferred to laboratory on ice. These samples were processed and 


\section{Open Access Journal of Veterinary Science \& Research}

homogenized in PBS buffer to make a $10 \%$ suspension and stored in freezer at $-20^{\circ} \mathrm{C}$.

\section{Isolation of Viral Nucleic Acid}

The RNA from fecal samples was extracted using RNAiso Plus reagent (Takara Bio Inc.) as per the manufacturer's instruction and the extracted RNA was resuspended in $20 \mu \mathrm{l}$ of nuclease free water and preserved at $-20^{\circ} \mathrm{C}$ until used.

\section{Oligonucleotide Primer Design}

The oligonucleotide primers used in the RT-PCR reaction were designed from the published sequence of Bovine Coronavirus trans-membrane (M) gene of Mebus strain (GenBank accession No. U00735). The M gene sequences of $\mathrm{BCoV}$ strains were retrieved from the Gen Bank database (http://www.ncbi.nlm.nih.gov/Genbank/i ndex.html). The primers were designed using the online NCBI primer designing tool to amplify a conserved 523bp fragment within $\mathrm{M}$ gene (Table 1).

\begin{tabular}{|c|c|c|c|c|}
\hline Primer name & Position & Sequence (5'-3') & No. of bases & Target gene and product size (bp) \\
\hline BCoV-MF & $32-51$ & ACACCTGGACTGCTGATGAA & 20 & M gene \\
\hline BCoV-MR & $554-535$ & TACGTGAGCAGGTGTGAGAC & 20 & $523 \mathrm{bp}$ \\
\hline
\end{tabular}

Table 1: List of Primers Used to Amplify Target Sequences of Corona Virus.

The primer was allowed for BLASTn (http://www.ncbi.nlm.nih.gov/BLAST) analysis in order to assess the specificity of primer for $\mathrm{M}$ gene of $\mathrm{BCoV}$.

\section{RT-PCR and PCR}

Extracted viral RNA was allowed for reverse transcription reaction and complementary DNA (cDNA) was prepared. Reverse transcription reaction was carried out in a $20 \mu \mathrm{L}$ reaction mixture containing $3 \mu \mathrm{L}$ of RNA sample $(1 \mu \mathrm{g} / \mu \mathrm{L}), 0.5 \mu \mathrm{L}$ of Random primer $(100 \mathrm{pMol})$, $1 \mu \mathrm{L}$ of DMSO ( $5 \%$ of final volume) and $3 \mu \mathrm{L}$ of nuclease free water. The tube was incubated at $95^{\circ} \mathrm{C}$ for $5 \mathrm{~min}$ and then quenched on ice for $5 \mathrm{~min}$. Subsequently, $4 \mu \mathrm{L}$ of $5 \times$ RT buffer, $2 \mu \mathrm{L}$ of $10 \mathrm{mM}$ dNTPs, $1.0 \mu \mathrm{L}$ (200 units/ $\mu \mathrm{L}$ ) of Moloney Murine Leukemia Virus (M-MULV) reverse transcriptase (Fermentas, USA) and sufficient nuclease free water was added to make final volume $20 \mu \mathrm{L}$. After allowing the primers to anneal at $25^{\circ} \mathrm{C}$ for $10 \mathrm{~min}$, reverse transcription was carried out at $37^{\circ} \mathrm{C}$ for $60 \mathrm{~min}$ in thermal cycler. The reverse transcriptase was heat inactivated at $70^{\circ} \mathrm{C}$ for $10 \mathrm{~min}$. The cDNA was stored at $20^{\circ} \mathrm{C}$ till further use. The cDNAs of all isolates were in turn used as template for $M$ gene specific PCR. The reaction conditions for amplification of $M$ gene through PCR were standardized in a gradient thermo cycler (Quanta Biotech) to get the desired specific product. The $20 \mu \mathrm{L}$ of PCR reaction mixture was prepared using $10 \mu \mathrm{L}$ of 2 X Top Taq master mix, 500nM of each forward and reverse primer, $6 \mu \mathrm{L}$ of nuclease free water along with $2 \mu \mathrm{L}$ of cDNA. The initial denaturation step was set at $94^{\circ} \mathrm{C}$ for $4 \mathrm{~min}$. The cyclic condition was set as denaturation at $94^{\circ} \mathrm{C}$ for $30 \mathrm{sec}$, annealing $55^{\circ} \mathrm{C}$ for $30 \mathrm{sec}$ and extension at $72^{\circ} \mathrm{C}$ for $45 \mathrm{sec}$ for 40 cycles. Final extension was given at $72^{\circ} \mathrm{C}$ for $7 \mathrm{~min}$. The amplified PCR products were subjected to $1.0 \%$ agarose gel electrophoresis and visualized on UV-trans illuminator (G-Biosciences, USA).

\section{Nucleic Acid Sequencing}

The PCR amplicons (523bp) of four samples (ABT/BF/16/Bocv86, ABT/BF/16/Bocv164, ABT/BF/16/Bocv167 and ABT/16/BF/BoCv183) were purified from agarose gels using ultra gel purification kit (Qiagen,USA) and submitted for bi-directional DNA sequencing using Big Dye Terminator kit 3.1 (Applied Biosystems $^{\mathrm{TM}}$ ) according to manufacturer's instructions. The sequencing was done using array based automatic capillary ABI 3130xL machine (Applied Biosystems ${ }^{\mathrm{TM}}$ ). The nucleotide sequences were analyzed using web based BlastN software (http://www.ncbi.nlm.nih.gov/BLAST). The contigs of nucleotide sequence were generated using Bioedit 7.2.8 programme [33]. Percent nucleotide identity of sequences in study along with global coronavirus strains of different species was calculated using Bioedit 7.2.8 and phylogenetic study was done using Mega 5 programme [34].

\section{Results}

Viral RNA was isolated using RNAiso Plus reagent (Takara Bio Inc.) from all the three hundred thirteen bovine fecal samples collected from diarrheic and nondiarrheic calves. The Viral RNA was allowed for cDNA synthesis for further processing of the samples.

\section{Detection of Coronavirus by RT-PCR}

The target sequences of $\mathrm{M}$ gene (523bp) were amplified using the primer pair (BCoV-MF and BCoV-MR) which is specific for conserved region in coronavirus 


\section{Open Access Journal of Veterinary Science \& Research}

(Figure 1). Out of total 313 samples screened by RT-PCR, $31(9.90 \%)$ samples were found positive for BCoV. Seven buffalo clinical cases of diarrheic fecal samples and 11 buffalo fecal samples collected from dairies farm in Hisar regions were shown positive for $\mathrm{BCoV}$. The viral infection in dairy farms of Bhiwani, Jind, Mewat, Umra, Mochiwala and Meerut was found to be $10 \%(2 / 20), 10 \%(1 / 10)$, $5.55 \%(2 / 36), 6.66 \%(2 / 30), 9.09 \%(3 / 33)$ and $7.5 \%$ $(3 / 40)$ respectively, with an overall prevalence of $9.90 \%$ (31/313) (Table 2 \& Figure 2).
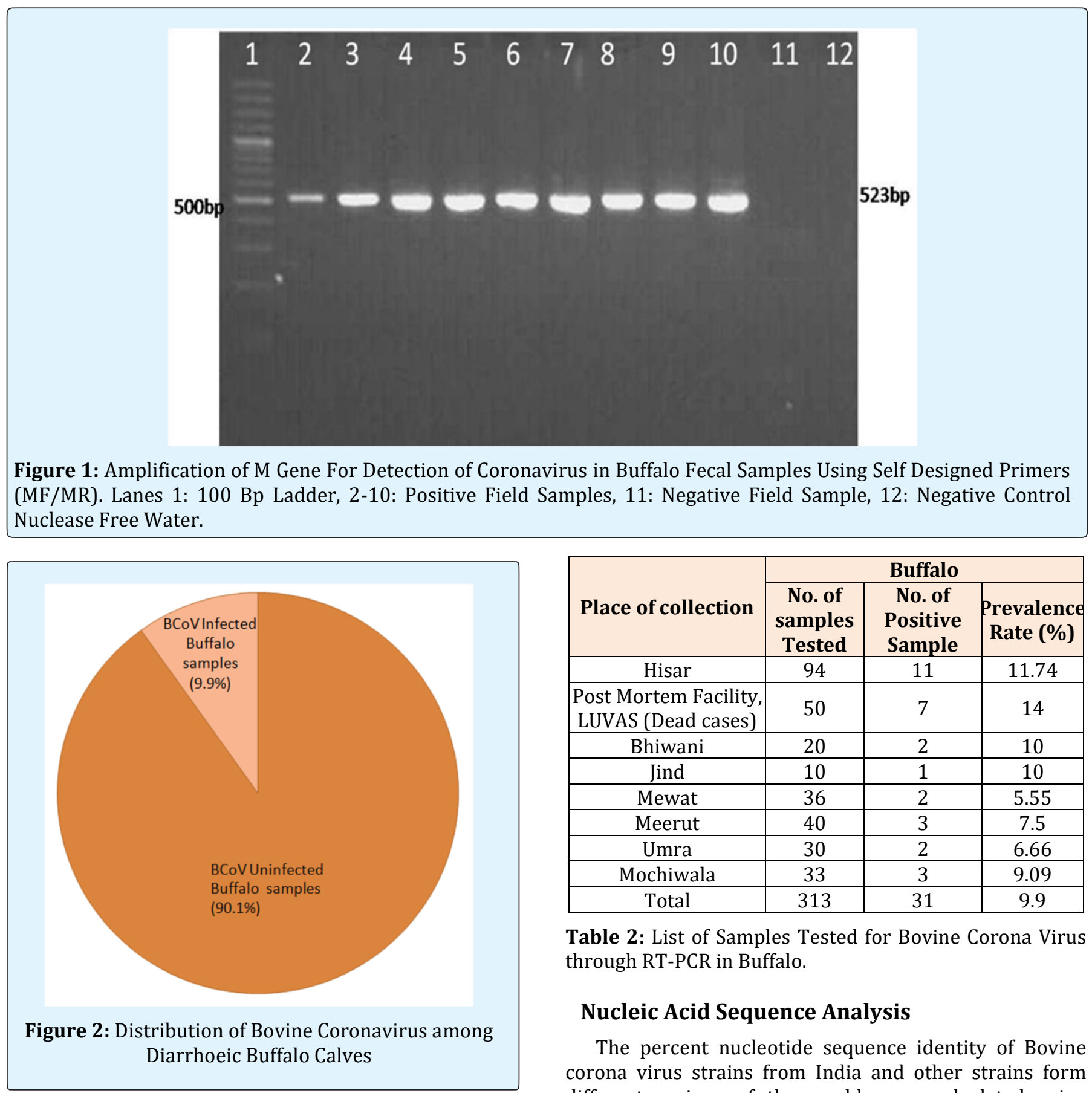

\begin{tabular}{|c|c|c|c|}
\hline \multirow{2}{*}{ Place of collection } & \multicolumn{3}{|c|}{ Buffalo } \\
\cline { 2 - 4 } & $\begin{array}{c}\text { No. of } \\
\text { samples } \\
\text { Tested }\end{array}$ & $\begin{array}{c}\text { No. of } \\
\text { Positive } \\
\text { Sample }\end{array}$ & $\begin{array}{c}\text { Prevalence } \\
\text { Rate (\%) }\end{array}$ \\
\hline Hisar & 94 & 11 & 11.74 \\
\hline $\begin{array}{c}\text { Post Mortem Facility, } \\
\text { LUVAS (Dead cases) }\end{array}$ & 50 & 7 & 14 \\
\hline Bhiwani & 20 & 2 & 10 \\
\hline Jind & 10 & 1 & 10 \\
\hline Mewat & 36 & 2 & 5.55 \\
\hline Meerut & 40 & 3 & 7.5 \\
\hline Umra & 30 & 2 & 6.66 \\
\hline Mochiwala & 33 & 3 & 9.09 \\
\hline Total & 313 & 31 & 9.9 \\
\hline
\end{tabular}

Table 2: List of Samples Tested for Bovine Corona Virus through RT-PCR in Buffalo.

\section{Nucleic Acid Sequence Analysis}

The percent nucleotide sequence identity of Bovine corona virus strains from India and other strains form different regions of the world were calculated using Bioedit 7.2.8 (Table 3). 


\begin{tabular}{|c|c|c|c|c|c|c|c|c|c|c|c|c|c|c|c|c|c|c|c|c|c|c|c|c|c|c|c|c|c|c|c|}
\hline S.n. & Coronavirus Sequences & $\mathbf{1}$ & 2 & 3 & 4 & 5 & 6 & 7 & 8 & 9 & 10 & 11 & 12 & 13 & 14 & 15 & 16 & 17 & 18 & 19 & 20 & 21 & 22 & 23 & 24 & 25 & 26 & 27 & 28 & 29 & 30 \\
\hline 1 & KX897159.1.Bovine coronavirus. ABT/16/BF/BoCv183.India & 100 & & & & & & & & & & & & & & & & & & & & & & & & & & & & & \\
\hline 2 & KX897160.1.Bovine coronavirus. ABT/BF/16/Bocv167.India & 98.3 & 100 & & & & & & & & & & & & & & & & & & & & & & & & & & & & \\
\hline 3 & KX897161.1.Bovine coronavirus. ABT/BF/16/Bocv164.India & 100 & 98.3 & 100 & & & & & & & & & & & & & & & & & & & & & & & & & & & \\
\hline 4 & KX897162.1.Bovine coronavirus. ABT/BF/16/Bocv86.India & 100 & 98.3 & 100 & 100 & & & & & & & & & & & & & & & & & & & & & & & & & & \\
\hline 5 & AB354579.1.Bovine coronavirus. Kakegawa. Japan & 100 & 98.3 & 100 & 100 & 100 & & & & & & & & & & & & & & & & & & & & & & & & & \\
\hline 6 & U00735.2.Bovine coronavirus. Mebus. USA & 100 & 98.3 & 100 & 100 & 100 & 100 & & & & & & & & & & & & & & & & & & & & & & & & \\
\hline 7 & AF058942.1.Bovine coronavirus.LY-138.USA & 99.7 & 98.5 & 99.7 & 799.7 & 99.7 & 99.7 & 100 & & & & & & & & & & & & & & & & & & & & & & & \\
\hline 8 & GQ918142.1.Canine respiratory coronavirus.K37.South Korea & 99.7 & 98 & 99.7 & 799.7 & 99.7 & 99.7 & 99.5 & 100 & & & & & & & & & & & & & & & & & & & & & & \\
\hline 9 & GQ918143.1.Canine respiratory coronavirus.K39.South Korea & 99.5 & 98.3 & 99.5 & 99.5 & 99.5 & 99.5 & 99.2 & 99.2 & 100 & & & & & & & & & & & & & & & & & & & & & \\
\hline 10 & KU886219.1. Bovine coronavirus. BCV-AKS-01.China & 99.2 & 98 & 99.2 & 99.2 & 99.2 & 99.2 & 99 & 99 & 99.2 & 100 & & & & & & & & & & & & & & & & & & & & \\
\hline 11 & AH014872.2. Bovine coronavirus. KWD7. South Korea & 99.2 & 98 & 99.2 & 99.2 & 99.2 & 99.2 & 99 & 99 & 99.2 & 100 & 100 & & & & & & & & & & & & & & & & & & & \\
\hline 12 & FJ938064.1.Bovine coronavirus. E-AH187-TC. USA & 99.2 & 98 & 99.2 & 99.2 & 99.2 & 99.2 & 99 & 99 & 99.2 & 100 & 100 & 100 & & & & & & & & & & & & & & & & & & \\
\hline 13 & FJ425187.1. White tailed deer coronavirus. US/OH-WD470/1994.USA & 99.2 & 98 & 99.2 & 99.2 & 99.2 & 99.2 & 99 & 99 & 99.2 & 100 & 100 & 100 & 100 & & & & & & & & & & & & & & & & & \\
\hline 14 & EF424623.1. Giraffe coronavirus. US/OH3/2003.USA & 99.2 & 98 & 99.2 & 99.2 & 99.2 & 99.2 & 99 & 99 & 99.2 & 100 & 100 & 100 & 100 & 100 & & & & & & & & & & & & & & & & \\
\hline 15 & EF424622.1. Giraffe coronavirus. US/OH3-TC/2006. USA & 99.2 & 98 & 99.2 & 99.2 & 99.2 & 99.2 & 99 & 99 & 99.2 & 100 & 100 & 100 & 100 & 100 & 100 & & & & & & & & & & & & & & & \\
\hline 16 & FJ425190.1. Sambar deer coronavirus. US/OH-WD388-TC/1994.USA & 99.2 & 98 & 99.2 & 99.2 & 99.2 & 99.2 & 99 & 99 & 99.2 & 100 & 100 & 100 & 100 & 100 & 100 & 100 & & & & & & & & & & & & & & \\
\hline 17 & FJ425189.1. Sambar deer coronavirus. US/OH-WD388/1994.USA & 99.2 & 98 & 99.2 & 99.2 & 99.2 & 99.2 & 99 & 99 & 99.2 & 100 & 100 & 100 & 100 & 100 & 100 & 100 & 100 & & & & & & & & & & & & & \\
\hline 18 & FJ425186.1. Waterbuck coronavirus. US/OH-WD358/1994. USA & 99.2 & 98 & 99.2 & 99.2 & 99.2 & 99.2 & 99 & 99 & 99.2 & 100 & 100 & 100 & 100 & 100 & 100 & 100 & 100 & 100 & & & & & & & & & & & & \\
\hline 19 & FJ425185.1.Waterbuck coronavirus. US/OH-WD358-GnC/1994. USA & 99.2 & 98 & 99.2 & 99.2 & 99.2 & 99.2 & 99 & 99 & 99.2 & 100 & 100 & 100 & 100 & 100 & 100 & 100 & 100 & 100 & 100 & & & & & & & & & & & \\
\hline 20 & KF530092.1. Human coronavirus. OC43/human/USA/008-5/2000.USA & 96.1 & 95.3 & 96.1 & 96.1 & 96.1 & 96.1 & 96.3 & 95.8 & 96.1 & 95.3 & 95.3 & 95.3 & 95.3 & 95.3 & 95.3 & 95.3 & 95.3 & 95.3 & 95.3 & 100 & & & & & & & & & & \\
\hline 21 & KF530078.1. Human coronavirus. OC43/human/USA/9612-29/1996.USA & 96.1 & 95.3 & 96.1 & 96.1 & 96.1 & 96.1 & 96.3 & 95.8 & 96.1 & 95.3 & 95.3 & 95.3 & 95.3 & 95.35 & 95.3 & 95.3 & 95.3 & 95.3 & 95.3 & 100 & 100 & & & & & & & & & \\
\hline 22 & KY014281.1. Human coronavirus. 2002-04. France & 96.1 & 95.3 & 96.1 & 196.1 & 96.1 & 96.1 & 96.3 & 95.8 & 96.1 & 95.3 & 95.3 & 95.3 & 95.3 & 95.35 & 95.3 & 95.3 & 95.3 & 95.3 & 95.3 & 100 & 100 & 100 & & & & & & & & \\
\hline 23 & KF530072.1.Human coronavirus. OC43/human/USA/9712-13/1997.USA & 96.1 & 95.3 & 96.1 & 96.1 & 96.1 & 96.1 & 96.3 & 95.8 & 96.1 & 95.3 & 95.3 & 95.3 & 95.3 & 95.35 & 95.3 & 95.3 & 95.3 & 95.39 & 95.31 & 1001 & \begin{tabular}{|l|l|l}
100 & 1 \\
\end{tabular} & \begin{tabular}{|l|l|l|l}
100 & 1 \\
\end{tabular} & 100 & & & & & & & \\
\hline 24 & KF530064.1. Human coronavirus. OC43/human/USA/9612-9/1996.USA & 96.1 & 95.3 & 96.1 & 196.1 & 96.1 & 96.1 & 96.3 & 95.8 & 96.1 & 95.3 & 95.3 & 95.3 & 95.3 & 95.3 & 95.39 & 95.39 & 95.39 & 95.39 & 95.31 & 1001 & 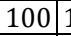 & 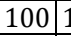 & \begin{tabular}{l|l}
100 & 1 \\
$r$
\end{tabular} & 100 & & & & & & \\
\hline 25 & KT368891.1. Camel coronavirus. Camel/Riyadh/Ry123/2015. Saudi Arabia & 98.7 & 99 & 98.7 & 98.7 & 98.7 & 98.7 & 99 & 98.5 & 98.7 & 98.5 & 98.5 & 98.5 & 98.5 & 98.5 & 98.5 & 98.5 & 98.5 & 98.59 & 98.59 & 95.89 & 95.89 & 95.89 & 95.89 & 95.8 & 3100 & & & & & \\
\hline 26 & KF906250.1. Dromedary camel coronavirus. HKU23-362F. UAE & 98.7 & 99 & 98.7 & 98.7 & 98.7 & 98.7 & 99 & 98.5 & 98.7 & 98.5 & 98.5 & 98.5 & 98.5 & 98.5 & 98.5 & 98.5 & 98.5 & 98.59 & 98.59 & 95.89 & 95.89 & 95.89 & 95.89 & 95.8 & 3100 & 100 & & & & \\
\hline 27 & KF906249.1. Dromedary camel coronavirus. HKU23-265F. UAE & 98.7 & 99 & 98.7 & 98.7 & 98.7 & 98.7 & 99 & 98.5 & 98.7 & 98.5 & 98.5 & 98.5 & 98.5 & 98.5 & 98.5 & 98.5 & 98.5 & 98.59 & 98.59 & 95.89 & 95.89 & \begin{tabular}{|l|l|l}
95.8 & 9 \\
\end{tabular} & \begin{tabular}{|l|l|l}
95.8 & 9 \\
\end{tabular} & 95.8 & 3100 & 100 & 100 & & & \\
\hline 28 & MF593476.1. Camel coronavirus. Can & 98.7 & 99 & 98.7 & 98.7 & 98.7 & 98.7 & 99 & 98.5 & 98.7 & 98.5 & 98.5 & 98.5 & 98.5 & 98.5 & 98.5 & 98.5 & 98.5 & 98.59 & 98.59 & 95.89 & 95.89 & \begin{tabular}{|c|c|c|}
95.8 & 9 \\
\end{tabular} & 95.89 & 95.8 & \begin{tabular}{|l|l|}
8 & 100 \\
\end{tabular} & 100 & 100 & 100 & & \\
\hline 29 & KT368891.1.Camel coronavirus. Camel/Riyadh/Ry123/2015. UAE & 98.7 & 99 & 98.7 & 98.7 & 98.7 & 98.7 & 99 & 98.5 & 98.7 & 98.5 & 98.5 & 98.5 & 98.5 & 98.5 & 98.5 & 98.59 & 98.59 & 98.59 & 98.59 & 95.89 & 95.89 & 95.89 & 95.89 & 95.8 & \begin{tabular}{|l|l|}
300 \\
\end{tabular} & 100 & 100 & 100 & 100 & \\
\hline 30 & KF906251.1. Dromedary camel coronavirus. HKU23-368F. UAE & 98.7 & 99 & 98.7 & 98.7 & 98.7 & 98.7 & 99 & 98.5 & 98.7 & 98.5 & 98.5 & 98.5 & $98.5 \mathrm{C}$ & 98.5 & 98.5 & 98.5 & $98.5[9$ & $98.5 \mid 9$ & 98.59 & 95.89 & 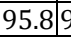 & \begin{tabular}{l|l|l|l}
95.8 & 9 \\
\end{tabular} & $95.8 \mid 9$ & 95.8 & \begin{tabular}{|l|l|}
8 & 100 \\
\end{tabular} & 100 & 100 & 100 & 100 & 10 \\
\hline
\end{tabular}

Table 3: Percent Nucleotide Sequence Analysis of Bovine Coronavirus M Gene Sequence with Global Strains of Coronavirus. 


\section{Open Access Journal of Veterinary Science \& Research}

Strains ABT/BF/16/Bocv86, ABT/BF/16/Bocv164 and $\mathrm{ABT} / 16 / \mathrm{BF} /$ Bocv183 showed maximum identity with bovine coronavirus strains and ABT/BF/16/Bocv167 with camelid corona virus strains. The phylogenetic analysis of Indian Bovine coronavirus strains with global strains of different species revealed that strains ABT/BF/16/Bocv86, ABT/BF/16/Bocv164 and $\mathrm{ABT} / 16 / \mathrm{BF} /$ Bocv183 form a separate clad with bovine coronavirus strains and ABT/BF/16/Bocv167 with camelid corona virus strains (Figure 3 ).

\section{Discussion}

The $\mathrm{BCoV}$ is associated with diarrhea in ruminants and it can infect young calves [35]. It causes severe loss to dairy industry. The early confirmation of $\mathrm{BCoV}$ in diarrheic cases is essential. In present study, we have reported the $\mathrm{BCoV}$ outbreak in India involving cattle herd irrespective of the age group. For virus detection in suspected samples primers specific to conserved regions ( $\mathrm{M}$ gene) of $\mathrm{BCoV}$ were designed. In our knowledge $\mathrm{M}$ gene based PCR assay for $\mathrm{BCoV}$ detection is quite rare. For molecular surveillance of $\mathrm{BCoV}$, bovine fecal samples were collected from different locations in India.

In our study, out of 313 fecal samples, RT-PCR based assay showed only thirty one (31) Buffalo fecal samples as positive for BCoV. Thus, $9.90 \%$ (31/313) prevalence of $\mathrm{BCoV}$ in dairy farms was observed. Moreover, higher incidence rate $(20 \%)$ of $\mathrm{BCoV}$ was reported in dead cases from postmortem room, LUVAS, Hisar. Our results showed that RT-PCR can be used for detection of BCoV in clinically normal calves also. Thus, RT-PCR based assay is a practical approach for epidemiological surveillance of $\mathrm{BCoV}$ in calves. It will provide sufficient time gap for implication of preventive measures in an animal farm prior to occurrence of diarrheic symptoms on animal. The RT-PCR assay develop in present study is sensitive enough to detect $\mathrm{BCoV}$ positive animals that might otherwise be classified as negative by other assays such as RNA-PAGE. The assay developed is easy to use and could be simultaneously used for screening of large number of clinical samples. Brandao, et al. also proved that $S$ gene based PCR assay is a specific and sensitive tool for bovine corona virus diagnosis [36]. Other genes base study such as $\mathrm{N}$ gene can also be employed for RT-PCR based detection of $\mathrm{BCoV}[10,37]$ in fecal samples. BCoV was detected in more than $57.8 \%$ of adult cattle suffering from diarrhea using RT-PCR method [38]. Decaro, et al. developed TaqMan based real-time RT-PCR assay for the rapid and sensitive diagnosis of BCoV infection [39]. Earlier report showed that $\mathrm{BCoVs}$ were also detected in adult cattle in several other countries [40]. Thus, our findings are in agreement with previous observations that BCoV strains circulating among the cattle [41]. The RTqPCR based recent study using nasal and fecal specimens of calves revealed that animal remain positive for $\mathrm{BCoV}$ infection for longer period than earlier reported [42].

The PCR amplicon of $\mathrm{BCoV}$ positive samples were sequenced. The nucleotide sequences of ABT/16/BF/Bocv183, ABT/BF/16/Bocv164, ABT/BF/16/Bocv86 and ABT/BF/16/Bocv167 strains were submitted to GenBank and accession numbers KX897159.1, KX897161.1, KX897162.1 and KX897160.1 respectively were assigned. The bovine coronavirus sequences showed 98.3-100\% nucleotide sequence identity among themselves (Table 3). Strains ABT/16/BF/Bocv183, ABT/BF/16/Bocv164 and ABT/BF/16/Bocv86 showed maximum nucleotide identity of $100 \%$ with bovine coronavirus strains from USA (strain Mebus) and Japan (strain, Kakegawa) [43] (Table 3). These strains also showed nucleotide identity of 98.7-99.5\% with several coronavirus strains from different species such as Bovine (E-AH187-TC, KWD7 and BCV-AKS-01) [44], Canine (K39), White-tailed deer (US/OH-WD470/1994) [45], Giraffe (US/OH3-TC/2006 and US/OH3/2003) [26], Sambar deer (US/OHWD388/1994 and US/OH-WD388-TC/1994) [45], Waterbuck (US/OH-WD358/1994) [45] and camelid (camel/Riyadh/Ry123/2015, HKU23-362F and HKU23$265 F)[23,46]$. They showed only $96.1 \%$ identity with human coronavirus strains (OC43/human/USA/961229/1996, OC43/human/USA/9612-9/1996, OC43/human/USA/9712-13/1997,

OC43/human/USA/008-5/2000, 2002-04/France). However, ABT/BF/16/Bocv167 strain showed maximum nucleotide identity of $99 \%$ with camelid strains (Camel/Riyadh/Ry123/2015, HKU23-362F, HKU23-265F, Camel/Abu Dhabi/B101 and Camel/Riyadh/Ry123/2015and HKU23-368F] [23,46]. ABT/BF/16/Bocv167 strain also showed 95.3-98.3\% nucleotide identity with coronaviruses of several other species such as bovine, canine, White-tailed deer, Giraffe, Sambar deer, Waterbuck and human. Thus, strain ABT/BF/16/Bocv167 might be of camelid origin and represent the cross species transmission of coronavirus from camel to bovine. The phylogenetic study also revealed that $\mathrm{ABT} / 16 / \mathrm{BF} / \mathrm{Bocv} 183$, ABT/BF/16/Bocv164 and ABT/BF/16/Bocv86 strains form a separate close cluster with bovine strains from USA (Mebus) and Japan (Kakegawa) (Figure 3). Other coronavirus strains from bovine, canine, White-tailed deer, Giraffe, Sambar deer, Waterbuck form a separate close cluster which was found closely related with this cluster. However, ABT/BF/16/Bocv167 strain formed a 
separate cluster along with camelid coronavirus strains (Figure 3). Human strains formed a separate close cluster. Thus, phylogenic study also revealed the camel origin of ABT/BF/16/Bocv167 strain. The phylogenetic studies of Alpacas (camilid) coronavirus (ACoV) suggest the common ancestor of camilid (alpacas) coronavirus (ACoV) and Bovine coronavirus (BCoV) [47]. Previous study has shown $>99.5 \%$ identity of genome of ACoV with BCoV (strains ENT and LUN) [47]. ACoV was also found closely related with other BCoV (Mebus, Quebec and DB2 strain) and human corona virus (strain 043) (identity $>96 \%$ ) [47]. Cross species transmissions of coronavirus were reported at several occasions throughout the world. In 2002-2003, severe outbreak of SARS was reported which killed around 800 people globally. Leen et al. (2005) suggested that, BCoV might have jumped the species barrier and became able to infect human, resulting in the emergence of a new type of human coronavirus (HCoV-OC43) and a scenario similar to the origin of the SARS outbreak [48]. The causative agent SARS-CoV was transmitted to human from its zoonotic reservoirs such as Himalayan palm civets (Paguma larvata), several bat species and raccoon dogs (Nyctereutes procyonoides) in China [49]. Recently, in Saudi Arabia three human lineages of MERS-Coronavirus (MERS-CoVs) have been reported form camelid, which indicates that camels serve as an important reservoir for MERS-CoVs which may lead to human infections [46]. Cross species transmission of CoVs are common. The scientific evidence of recent MERS-CoV outbreak to human population by zoonotic transmission from camels is reported [50].

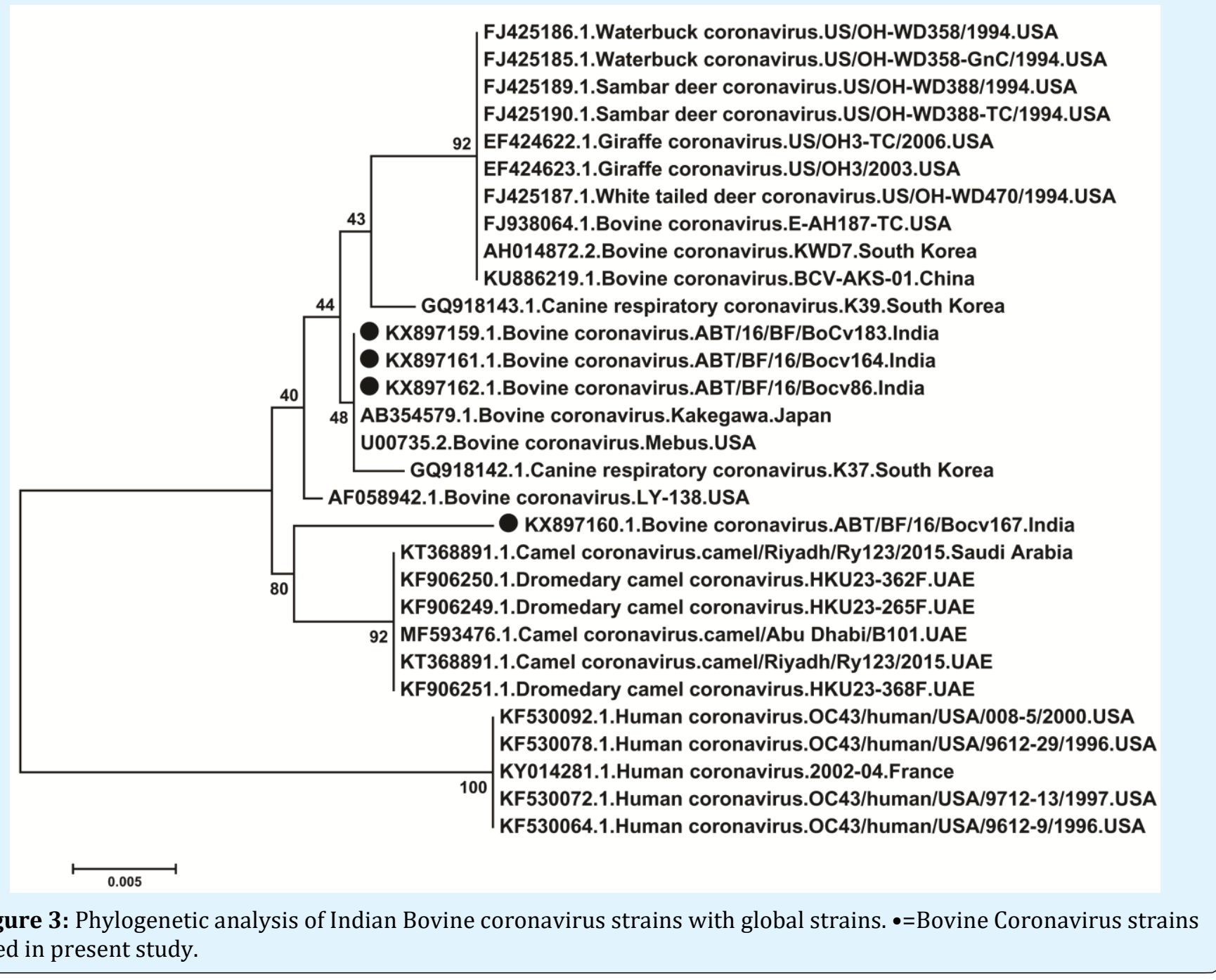

Minakshi P, et al. Jumping of Camelid Coronavirus in Bovines: A Report from Rural Area of Haryana, India. Vet Sci Res 2019, 4(3): 000183. 


\section{Open Access Journal of Veterinary Science \& Research}

The control of Coronavirus is a difficult task. BCoV usually persists for longer period in host body. Experimental study proved the persistence and detection of $\mathrm{BCoV}$ in Holstein cattle calves even after 1,085 days of post infection using RT-PCR and nested PCR assays [51]. Moreover, cross host transmission of CoVs are challenging tasks for control of its outbreak. BCoV has been identified from several other species of domesticated ruminant animals (sheep, goat, water buffalo, dromedary camel, llama and alpaca) and wild ruminants (antelopes, giraffes, deer, wild cattle and wild goats) [52].

\section{Conclusion and Future Perspective}

The outbreak described in this paper highlights the need for molecular investigations on BCoV infection in Indian bovine herds. Out of 313 suspected samples, 31 samples of buffalo origin were found infected with bovine coronavirus by PCR using M gene specific primers. Interspecies transmission of coronavirus was observed which could be first report of transmission of coronavirus of camelid origin to bovines. Recent reports on detection of camelid coronavirus from infected human and buffalos is alarming as, it is suggestive of zoonotic transmission. This shows the conflict of animals and humans for sharing living space in urban as well as sub-urban areas. Hisar is on the border of Rajasthan state and hence mixing of camel and buffalo population may pose high risk of interspecies transmission of coronaviruses. In order to reduce mortality and economic losses caused by $\mathrm{BCoV}$, diagnosis of viral infection at early stage in addition to vaccination and good management should be practiced. However, further study using isolation of infectious virus in cell culture and sequencing of the whole genome of virus may be performed to conclude migration of coronavirus between camelid and bovine species.

\section{Acknowledgment}

Authors are highly thankful to All India Network Project on Neonatal Mortality in Farm Animals (AINPNM), ICAR, for financial support and Department of Animal Biotechnology for providing necessary facilities to carry out this work.

\section{References}

1. Cho KO, Yoon SS (2014) An overview of calf diarrhea infectious etiology, diagnosis, and intervention. J Vet Sci 15(1): 1-17.

2. Dhama K, Chauhan RS, Mahendran M, Malik SV (2009) Rotavirus infection in bovines and other domesticated animals: A Review. Vet Research Commun 33(1): 1-23.

3. Gumusova SO, Yazici Z, Albayrak H, Meral Y (2007) Rotavirus and coronavirus prevalence in healthy calves and calves with diarrhea. Medycnya Weterinaria 63(1): 62-64.

4. Izzo MM, Kirkland PD, Mohler VL, Perkins NR, Gunn AA, et al. (2011) Prevalence of major enteric pathogens in Australian dairy calves with diarrhoea. Aust Vet J 89(5): 167-173.

5. Malik S, Verma AK, Kumar A, Gupta MK, Sharma SD (2012) Incidence of calf diarrhea in cattle and buffalo calves in Uttar Pradesh, India. Asian Journal of Animal and Veterinary Advances 7(10): 1049-1054.

6. Uhde FL, Kaufmann T, Sager H, Albini S, Zanoni R, et al. (2008) Prevalence of four enteropathogens in the faeces of young diarrhoeic dairy calves in Switzerland. Vet Record 163(12): 362-366.

7. Weiss SR, Navas-Martin S (2005) Coronavirus pathogenesis and the emerging pathogen severe acute respiratory syndrome coronavirus. Microbiology and Molecular Biology Reviews 69(4): 635-664.

8. Gunn AA, Naylor JA, House JK (2009) Diarrhea. In manifestations and management of disease in neonatal ruminants. In: Smith BP, (Ed.), Large animal internal medicine, $4^{\text {th }}$ (Edn.), Mosby Elsevier, St. Louis, MO, pp: 340-362.

9. Boileau MJ, Kapil S (2010) Bovine coronavirus associated syndromes. Vet Clinics North America Food Animal Practice 26(1): 123-146.

10. Gomez DE, Arroyo LG, Poljak Z, Viel L, Weese JS (2017) Detection of Bovine Coronavirus in Healthy and Diarrheic Dairy Calves. J Vet Intern Med 31(6): 1884-1891.

11. Saif LJ (2010) Bovine Respiratory Coronavirus. Vet Clin Food Anim 26(2): 349-364.

12. Vijgen L, Keyaerts E, Lemey P, Maes P, Reeth VK, et al. (2006) Evolutionary history of the closely related group 2 coronaviruses: porcine hemagglutinating encephalomyelitis virus, bovine coronavirus, and human coronavirus OC43. J Virol 80(14): 7270-7274. 


\section{Open Access Journal of Veterinary Science \& Research}

13. Perlman S, Netland J (2009) Coronaviruses postSARS: update on replication and pathogenesis. Nat Rev Microbiol 7(6): 439-450.

14. Yang D, Leibowitz JL (2015) The structure and functions of coronavirus genomic $3^{\prime}$ and $5^{\prime}$ ends. Virus Res 206: 120-133.

15. Graham RL, Donaldson EF, Baric RS (2013) A decade after SARS: strategies for controlling emerging coronaviruses. Nat Rev Microbiol 11(12): 836-848.

16. Van Regenmortel MHV, Fauquet CM, Bishop DHL, Carstens EB, Estes MK, et al. (2000) Virus Taxonomy: Classification and Nomenclature of Viruses. Academic Press, pp: 1162.

17. Saif LJ (1993) Coronavirus immunogens. Vet Microbiol 37(3-4): 285-297.

18. Mebus CA, Stair EL, Rhodes MB, Twiehaus MJ (1973) Neonatal calf diarrhea: Propagation, attenuation and characteristics of a coronavirus-like agent. American J Vet Res 34(2): 145-150.

19. Snodgrass DR, Terzolo HR, Sherwood D, Campbell I, Menzies JD, et al. (1986) Aetiology of diarrhea in young calves. Vet Rec 119(2): 31-34.

20. Park SJ, Kim GY, Choy HE, Hong YJ, Saif LJ, et al. (2007) Dual enteric and respiratory tropisms of winter dysentery bovine coronavirus in calves. Arch Virol 152(10): 1885-1900.

21. Fulton RW, Step DL, Wahrmund J, Burge LJ, Payton ME, et al. (2011) Bovine coronavirus (BCV) infections in transported commingled beef cattle and solesource ranch calves. Can J Vet Res 75(3): 191-199.

22. Lau SK, Woo PC, Li KS, Tsang AK, Fan RY, et al. (2015) Discovery of a novel coronavirus, China Rattus coronavirus HKU24, from Norway rats supports the murine origin of Betacoronavirus1 and has implications for the ancestor of Betacoronavirus lineage. Am J Virol 89(6): 30763092.

23. Woo PC, Lau SK, Werner U, Wong EY, Tsang AK, et al. (2014) Novel betacoronavirus in dromedaries of the Middle East, 2013. Emerg Infect Dis 20(4): 560-572.

24. Lau SK, Lee P, Tsang AK, Yip CC, Tse H, et al. (2011) Molecular epidemiology of human coronavirus OC43 reveals evolution of different genotypes over time and recent emergence of a novel genotype due to natural recombination. J Virol 85(21): 11325-11337.

25. Zhang XM, Herbst W, Kousoulas KG, Storz J (1994) Biological and genetic characterization of a hemagglutinating coronavirus isolated from a diarrhoeic child. J Med Virol 44(2): 152-161.

26. Hasoksuz M, Alekseev K, Vlasova A, Zhang X, Spiro D, et al. (2007) Biologic, antigenic, and full-length genomic characterization of a bovine-like coronavirus isolated from a giraffe. J Virol 81(10): 4981-4990.

27. Ismail MM, Cho KO, Ward LA, Saif LJ, Saif YM (2001) Experimental bovine coronavirus in turkey poults and young chickens. Avian Dis 45(1): 157-163.

28. Fan Y, Zhao K, Shi ZL, Zhou P (2019) Bat Coronaviruses in China. Viruses 11(3): E210.

29. Khalili M, Morshedi A (2006) The first detection of bovine coronavirus in calves diarrhea in West of Iran J Clinical Virol 36: S24-S25.

30. Takiuchi E, Stipp DT, Alfieri AF, Alfieri AA (2006) Improved detection of bovine coronavirus $\mathrm{N}$ gene in faeces of calves infected naturally by asemi-nested PCR assay and an internal control. J Virol Methods 131(2): 148-154.

31. Dash SK, Kumar K, Goel A, Bhatia AK (2012) Detection of corona virus antigen by ELISA from diarrhoeic cow calves in Mathura, India. Vet World 5(3): 166-168.

32. Hansa A, Rai RB, Dhama K, Wani MY (2012) ELISA and RT-PCR based detection of bovine coronavirus in Northern India. Asian J Animal Vet Adv 7(11): 11201129.

33. Hall TA (1999) BioEdit: A user-friendly biological sequence alignment editor and analysis program for Windows 95/98/NT. Nucl Acids Symp Ser 41: 95-98.

34. Tamura KD, Peterson N, Stecher G, Nei M, Kumar S (2011) MEGA5: Molecular Evolutionary Genetics Analysis using Maximum Likelihood, Evolutionary Distance, and Maximum Parsimony Methods. Mol Biol Evo 28(10): 2731-2739.

35. Quinn PJ, Markey BK, Carter ME, Donnelly WJ, Leonard FC (2002) Veterinary Microbiology and Microbial Diseases. $1^{\text {st }}$ (Edn.), Blackwell Science publishing, pp: 419-420. 
36. Brandao PE, Gregor GS, Monteleoni RM, Soares CA, Rosales CA, et al. (2003) Nested PCR assay for detection of Bovine Coronavirus S1 gene. Sao Paulo Arq Inst Biol 70: 1-3.

37. Akkara TS, Mini M, Priya PM, Ravishankar C, Ajithkumar S, et al. (2018) Detection of bovine coronavirus from a private farm in thrissur, kerala using reverse transcriptase Polymerase chain reaction. Inter J Sci Env Tech 7(4): 1453-1456.

38. Mawatari T, Hirano K, Ikeda H, Tsunemitsu H, Suzuki $\mathrm{T}$ (2014) Surveillance of diarrhea-causing pathogens in dairy and beef cows in Yamagata Prefecture, Japan from 2002 to 2011. Microbiol Immunol 58(9): 530535.

39. Decaro N, Elia G, Campolo M, Desario C, Mari V, et al. (2008) Detection of bovine coronavirus using a TaqMan-based real-time RT-PCR assay. J Virol Methods 151(2): 167-171.

40. Liu L, Hagglund S, Hakhverdyan M, Alenius S, Larsen LE, et al. (2006) Molecular epidemiology of bovine coronavirus on the basis of comparative analyses of the S gene. J Clin Microbiol 44(3): 957-60.

41. Park SJ, Jeong C, Yoon SS, Choy HE, Saif LJ, et al. (2006) Detection and characterization of bovine coronaviruses in fecal specimens of adult cattle with diarrhea during the warmer seasons. J Clin Microbiol 44(9): 3178-3188.

42. Oma VS, Traven M, Alenius S, Myrmel M, Stokstad M (2016) Bovine coronavirus in naturally and experimentally exposed calves; viral shedding and the potential for transmission. Virology Journal 13: 100.

43. Kanno T, Hatama S, Ishihara R, Uchida I (2007) Molecular analysis of the $S$ glycoprotein gene of bovine coronaviruses isolated in Japan from 1999 to 2006. J Gen Virol 88(4): 1218-1224.

44. Ko CK, Kang MI, Lim GK, Kim GY, Yoon SS, et al. (2006) Molecular characterization of $\mathrm{HE}, \mathrm{M}$, and $\mathrm{E}$ genes of winter dysentery bovine coronavirus circulated in Korea during 2002-2003. Virus Genes 32(2): 129-136.

45. Alekseev KP, Vlasova AN, Jung K, Hasoksuz M, Zhang $\mathrm{X}$, et al. (2008) Bovine-like coronaviruses isolated from four species of captive wild ruminants are homologous to bovine coronaviruses, based on complete genomic sequences. J Virol 82: 1242212431.

46. Sabir JS, Lam TT, Ahmed MM, Li L, Shen Y, et al. (2016) Co-circulation of three camel coronavirus species and recombination of MERS-CoVs in Saudi Arabia. Science 351(6268): 81-84.

47. Jin L, Cebra CK, Baker RJ, Mattson DE, Cohen SA, et al. (2007) Analysis of the genome sequence of an alpaca coronavirus. Virology 365(1): 198-203.

48. Leen V, Els K, Elien M, Inge T, Elke W, et al. (2005) Complete genomic sequence of human coronavirus 0C43: molecular clock analysis suggests a relatively recent zoonotic coronavirus transmission event. J Virol 79(3): 1595-1604.

49. Graham RL, Baric RS (2010) Recombination, reservoirs, and the modular spike: mechanisms of coronavirus cross-species transmission. J Virol 84: 3134-3146.

50. Reusken CB, Raj VS, Koopmans MP, Haagmans BL (2016) Cross host transmission in the emergence of MERS coronavirus. Curr Opin Virol 16: 55-62.

51. Kanno T, Ishihara R, Hatama S, Uchida I (2018) A long-term animal experiment indicating persistent infection of bovine coronavirus in cattle. J Vet Med Sci 80(7): 1134-1137.

52. Amer HM (2018) Bovine-like coronaviruses in domestic and wild ruminants. Anim Health Res Rev 19(2): 113-124. 